\title{
Renovation of the historic building after damage connected with foundations subsidence - case study
}

\author{
Janusz Ukleja,* \\ Faculty of Civil Engineering and Architecture, Opole University of Technology, \\ 45-061 Opole, ul. Katowicka 48, Poland
}

\begin{abstract}
The paper delineates the study of a historic building renovation. It was built in 1900 and completed in 1939. Its both parts consist of different constructions. The old part was founded very deeply whereas the level of the younger part foundations was higher than the old one. After large floods, the walls started to crack, elements of the ceilings and roof under the extended part of the building slipped. It was expected that in the future a construction disaster would pose a serious probability of occurrence. In the study it was necessary to recognize the entire construction with a thorough investigation of the underground, old part of it and also the soil types density were examined. The main objective of the new research was to define the real reasons of the damage and to determine the possibility of repairing this building. The elaboration of the study results revealed a conception of supporting the walls of the building. The results indicated that the need to verify the reasons of the occurring damage in a complex and thorough way is tremendous, especially when a monument is concerned which was developed in stages in various historical periods.
\end{abstract}

\section{Introduction}

\subsection{General characteristics and the history of the building elevation}

The following article delineates external factors significantly influencing the durability as well as serviceability of construction works on the example of a damaged, historical facility belonging to the premises of the Medical University in Wroclaw.

Many researchers have dealt with this or similar subject matter in different countries, for example [4-7] .The analysis performed in order to reveal the actual reasons of destructive forces includes not only their deascription and delineation of the engineering countermeasures but also discussion on the natural and anthropogenic factors impact on the general damage. These factors were neglected during the intermittent process of previously conducted reconstruction and renovation proceedings of the building.

\footnotetext{
* Corresponding author: ukleja2012@gmail.com
} 
a) Facade of the building east wall

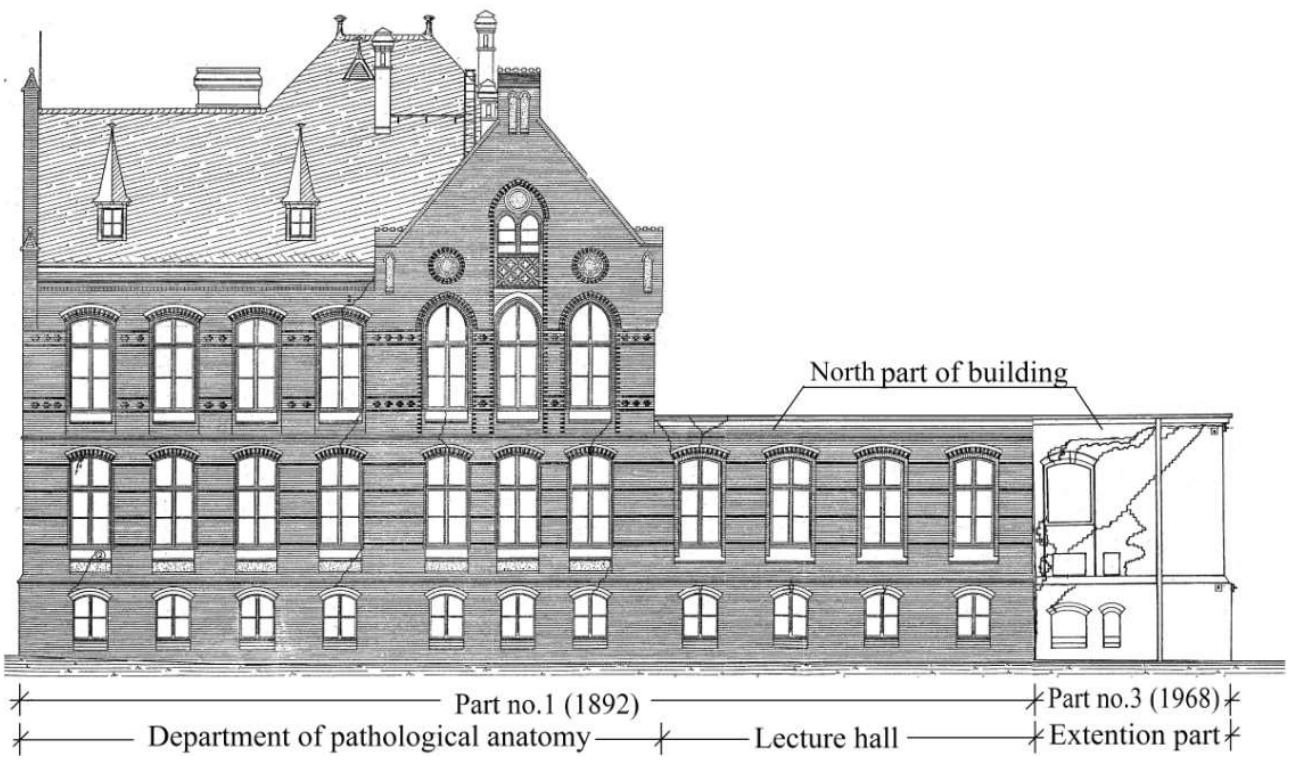

b) Situational plan and distribution of the building's sections

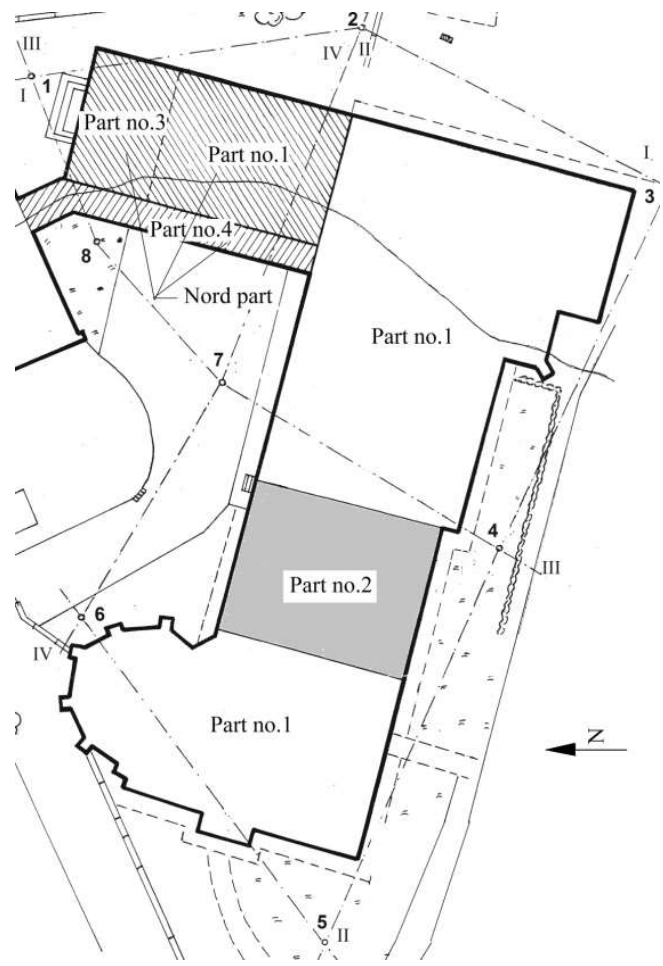

Fig. 1. Parts of the studied historical building (Part no.1- Division of general pathology (1898); Part no.2- the Connector building (1929); Part no. 3 - the Extention (1938); Part no. 4 - the Connector (1968); I-I $\div$ IV-IV - geotechnical crosssection lines; $1 \div 8$ - boreholes and research sensors sites). 
The land, where the studied building was placed, was initially a flood retention basin of the Odra river. One of its estuaries still flows in the close neighbourhood of the building. The groundwater level in this site has always indicated serious fluctuations values ranging to about $6 \mathrm{~m}$. In the preconstruction phase, the land was subject to substantial irrigation works and it was considerably elevated with the non-territorial soils. In 1882 the studied building was erected on this area and extended in four stages till 1968. The analysis of historical archives, available expertise studies and elaborations uncovered the over one-hundred-year history of the anatomy building and its four-stage implementation process:

1) Phase I - involving the main part of the building and its north wing (Part no. 1) designed and implemented in years $1892-1898$ as a brick construction with vaulted roofs also made of brick. In the original building, the Lecture hall situated on the high groundfloor - due to its small size $(9.28 \times 8.42 \mathrm{~m})$ had horizontal floor surface with one entrance from the corridor of the main building. Initially, it was able to accommodate only 84 students and after the enlargement of the building in 1938 it could provide place for as many as 132 students and then 180 students. The roof over the north wing was made of timber and beams with bilateral slopes. Similarly, the envelope of the entire original building represents a unitary nature in case of the architectural design. The facilities of the pathology department together with the north wing were founded at the depth of about $5.3 \mathrm{~m}$ measured from the current level of the terrain (it approximates the low level of water in the Old Odra river), on a stable ground surface with intact structure made of consolidated coarse sands and sandy gravel. The loadbearing walls are made of bricks, they are $0.64 \mathrm{~m}$ thick at the ground and Lecture hall levels, and supported below the ground by the foundamental brick walls, about $1 \mathrm{~m}$ thick, constructed in a form of a multi-span sequence of brick vaultings (Fig.2). The foundation wall pillars are braced on massive foundations. The discussed part of the building was stable with no manifestations of uneven subsidence cases.

2) Phase II - The second stage of works referred to years 1926-1929 when the Connector building was constructed between the main building (Part no. 2) and the building encompassing a circular forensic room forming a common, joint facility for the Pathology Institute. Both the Connector facade and its construction were adapted to match the two pre-existing buildings as far as the architectonic unity was concerned. Due to a good stability, the part of the building which was constructed and placed analogically to Part no.1 did not an pose any exploitation challenges.

3) Phase III - The third stage referred to years 1935-1938 when the north wing of the building (Part no.3), which was housing the Lecture Hall, was extended to the north by $6.66 \mathrm{~m}$ with the Extension building connected with the current part of the building. (Fig. 1 and 2). The constructed extension of the north wing resulted not only in an enlargement of the entire structure but also it changed its character in terms of utility and constructional - architectonical measures. The Lecture hall situated on the high groundfloor was extended by $2.8 \mathrm{~m}$ and amended from a horizontal in character into amphitheatrical one. Moreover, in the backroom space in its north side, a staircase was constructed together with lavatories with a separate entrance from the north. However, the extended part of the north wing was unprofessionally performed.

A few serious mistakes examples can be noticed here as far as the engineering and construction expertise are concerned:

a) the Extension which was a separate construction unit was covered with a common, joint and monolith ceiling and roof under the Lecture hall without dilatation what usually led to crackings even if the foundament conditions were equal in case of both neighbouring buildings.

b) the Extension was placed about $2.20 \mathrm{~m}$ higher than the original building. Its foundations were much thinner (by about $0.45 \mathrm{~m}$ ) despite placing it on the ground 
with much lower bearing capacity (soft-plastic, coated silts) than the soil under the main building (coarse sands and consolidated sandy gravel of intact structure)

c) the Extension was placed on the area characterised by a fluctuation levels of groundwaters depending on the water level of the nearby Old Odra, only $10 \mathrm{~m}$ away. Whereas, the original building was placed below the level of groundwaters volatility.

d) because of the fact that the level of the Extension foundaments placement was much higher than the riverbed and the basement of the original building, it enabled the phenomenon of suffosion of foundational frame to take place. Such an issue may occur with any significant river level volatility ranging from flood level to low level (twice a year on average). Suffosion, appearing collectively with the malconstructions discussed above, is regarded to be the main reason of uneven subsidence of the building elements as well as the occurring damage.

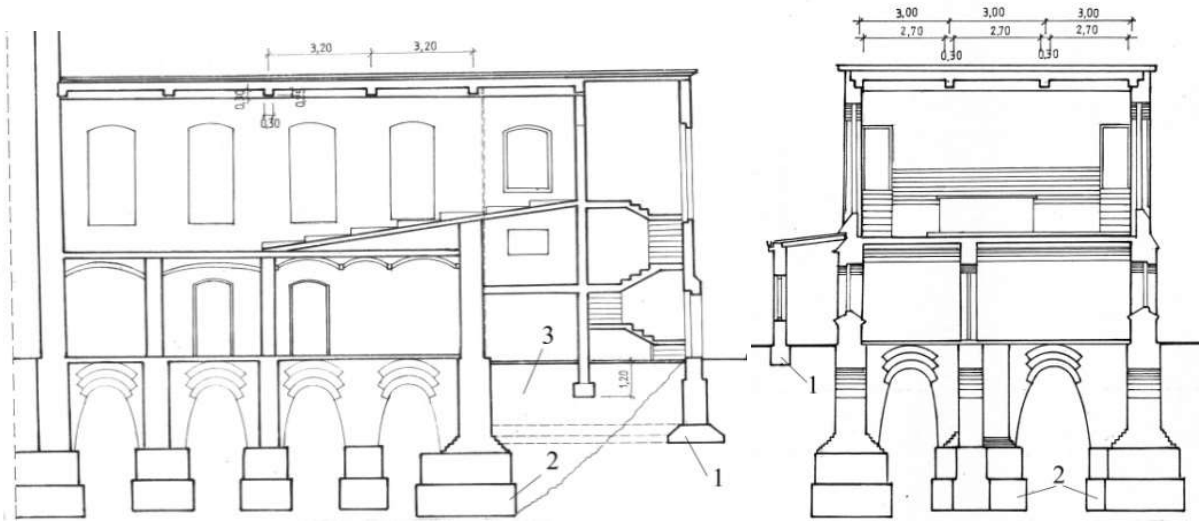

Fig. 2. Vertical cross-sections of the north wing of the building (the Lecture hall - Part no.1 and the Extension - Part no. 3; 1 - foundations of the Extension; 2- simple column footing of the Lecture hall; 3- foundament wall of the Extension).

4) Phase IV - in the fourth stage, the Connector building was executed (Part no.4) between the pathological anatomy building and the animal lab in the $1965-1968$. It was a one-storey building, with no basements constructed in a form of an enlargement along the west wall of the pathological anatomy building north wing. Its construction was based on the reinforced concrete slab of the roof supported by the anatomy building wall on one side and by the $0.38 \mathrm{~m}$ - thick brick wall on the other. The outer wall was propped on a circa $0.40 \mathrm{~m}$-thick concrete wall footing, recessed only $0,6 \mathrm{~m}$ below the terrain level (Fig. 2). During the process of founding the Connector, a few serious inaccuracies belonging to the art of building can be recorded:

a) the outer wall placement of the building was too shallow since the frost-free depth was not obtained at minimum,

b) the ground of the external wall consisted of a thick layer of anthropogenic materials of uncontrolled bulk density (from loose in nature to mildly compacted),

c) a considerable part of the ground consisted of anthropogenic materials such as softplastic silts with an addition of organic elements,

d) the roof of the Connector (Part no. 4) was supported by the walls with three different foundation measures: the original building was firmly founded on a stable ground; the walls of the Extension building were supported by unstable silts characterised by fluctuating humidity conditions; the outer wall of the Connector with the conditions discussed above. 
The combination of the described factors impact led to the appearance of serious damage of the Connector after years.

\subsection{The way of settling the building foundations and corresponding issues}

The construction of the major building took place in the period of 1892-1898 and covered the western part of the premise up to the so-called Extension (Part no.3). The undergrounds of the north wing were not filled with soils whereas the foundations of the load bearing walls were settled at the depth of about $5.3 \mathrm{~m}$ below the terrain level. The data obtained during the research drilling indicates that the discussed part of the building was founded on the compacted coarse sands and sandy gravels characterised by a high bearing value, thus, it indicated an adequate value of stability conditions.

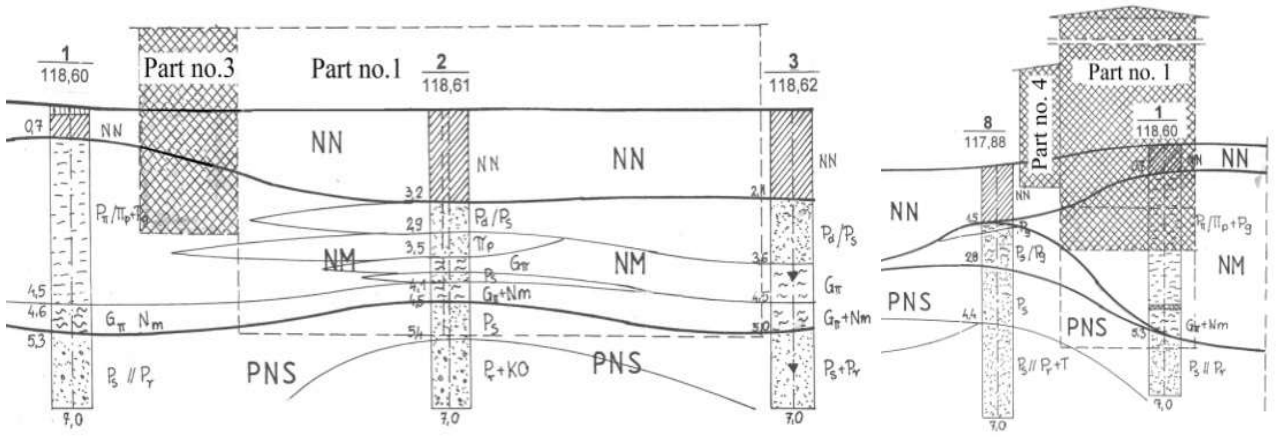

Fig. 3. Geotechnical cross-section of the soils under the north part of the building (NN- uncontrolled soil mounting ; NM- anthropogenic soils and malcompacted silts overcoated with organic materials; PNS- stable ground (compacted sandy gravel, gravel and rubble).

Between 1934 and 1939, the Extension was constructed as the back part of the Lecture hall and the north staircase together with the adjacent lavatories. The Extension is a nonbasement structure and its foundations were settled about $2.0 \mathrm{~m}$ higher than the older part of the main building, what resulted in an extremely disadvantageous stability conditions. It was also estimated that a 2-meter-thick residual layer of soft-plastic sandy soils susceptible to displacement under a load tension was present under the foundations of the Extension. That layer was intact in nature. It was formed by uncontrolled mounting of soils mainly consisting of sandy soils and silts with a considerable amount of organic elements. This layer did not spread evenly and its sedimentary volume of thickness was lower under the middle part of the walls. As a result, a "hump" (warping) occurred uder the middle part of the transverse walls belonging to the Extension and it manifested more advantageous load bearing conditions. Another result of this phenomenon was a lower level of subsidence recorded for the middle part in comparison to the corners. It was obviously interpreted according to the character and size of the tear lines and cracks visible inside the building (Fig. 4).

Frequent fluctuations of the underground water levels of about $6 \mathrm{~m}$ amplitude as well as the presence of empty underground spaces in connection with the leaking and cracking walls of the north wing contributed to 5uffusion occurrence manifested by uplifting small constituents of the underground framework to the surface. This time, it was interpreted with the formation of empty spaces under the flooring in the ground-level rooms in the extended part of the wing. The conducted comparative analysis of the geological and engineering structure of the ground and the cracks of foundament walls within the studied building revealed that: 
a) the original, main building (Part no.1) was deeply settled (over 5.0m deeper than the current terrain level), on stable brick foundations and on firm ground (compacted sandy gravel, gravel and rubble PNS (Fig. 3), below the lowest water table level in the neighbouring riverbed of the Old Odra,

b) the Extension of the north wing of the building, comprising additional stairs, lavatories and a part of the Lecture hall (Part no. 3), was settled much higher in the ground (by over $2.0 \mathrm{~m}$ ) then the adjacent original building on the ground reflected by a poor value of bearing capacity NM (anthropogenic soils and inadequately compacted sandy soils overcoated with organic elements and with fluctuating consistency: ranging from softplastic to liquid depending on the water level of the Old Odra),

c) the Connector (Part no.4) was settled on the depth of only $6 \mathrm{~m}$ on the anthropogenic soils NM in a form of uncontrolled mounting with sites of poor compaction structure reflecting a local cavernous character prone to uneven subsidence, especially at times of water level fluctuations in the Old Odra and during the high flooding levels.

\section{Input data of the building technical conditions and causes identification of the emerging damage}

\subsection{Technical condition of the pathological anatomy original building.}

It was assessed that the technical condition of the pathological anatomy building was generally stable as regards its foundations. The thin crack lines which emerged during over a hundred year old exploitation of that part of the building (Fig.1 and 4) did not constitute any hazardous implications for the construction. Nevetheless, they required to be eliminated with the submerged injection method under pressure for the sake of sustaining the continuity of walls.

\subsection{Technical condition of the Extension building to the north wing.}

This part of the pathological anatomy building was constructed before the II World War (years 1936-1938) and constituted the major destabilization cause for the entire studied object. A whole range of misconceptions concerning the foundations settlement of the Extension accounted for the preconditions of the emerging destruction phenomena (Part no.3) and they can be characterised as follows:

- the building was placed on a thick layer (approx. 3.0m) of sandy, soft-plastic and liquid soils of intact structure which should not have formed the construction ground,

- column footings were settled $3.0 \mathrm{~m}$ higher than the foundations of the adjacent main building that was constructed earlier what highlights the fact that the Extension ground had already been interrupted during the construction process of the original building,

- the dilatation between the Extension (Part no.3) and the original building (Part no.1) was performed unprofessionally despite various settlement conditions and ground parameters. It induced uneven subsidence events of non-dilatated building parts resulting in the occurrence of wall cracking from the very beginning,

- the impact of the ground water levels fluctuation depending on the Odra river level was not taken into account. The changeability of the river levels boosted uneven ground subsidence under both parts of the premise which was, additionally, subject to diverse load bearing values and was settled on the soil with different load capacities and subsidence values. 
a) Tear lines and crackings of the north part of the building on its east facade

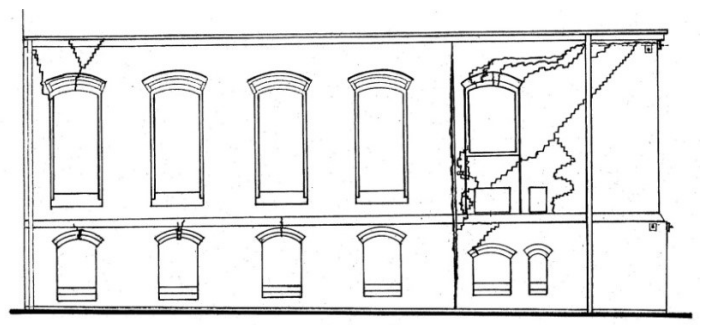

b) Wall and foundation deformations of the north part of the building
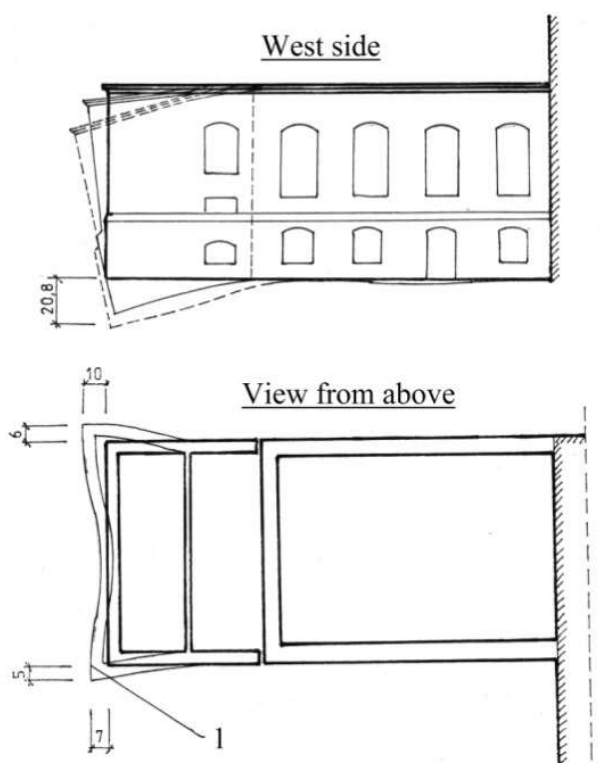

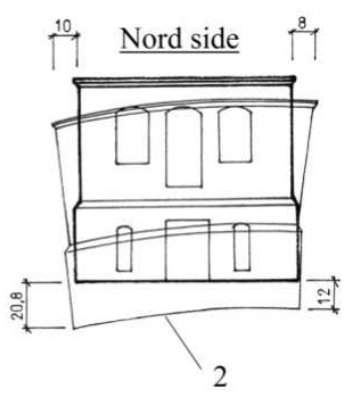

Deformation scale

$\longdiv { 1 0 2 0 3 0 \mathrm { cm } }$

Fig. 4. The building damage caused by uneven foundation subsidence (1- shape of vertical walls deformation, 2- shape of the foundation deformation).

\section{Renovation and repair works}

Although the entire building may be depicted as a coherent entity as regards its outward architectonical style, its elements required individual approach to renovation and repair works. The technical data analysis of the entire building enabled to confirm that the majority of its elements which were constructed till the year 1926 (Part no. 1 and 2) did not present any hazards according to the construction permanence and it should have undergone only minor repairs. They involved filling in chipping defects as well as injecting cracks with small openings and typical renovation operations applied to these kinds of historical objects. The remaining parts, especially the Extension, also required major repairs of the building construction before being submitted to similar analogical renovation works. 


\subsection{Generally applicable recommendations for reconstruction of the entity}

Due to the occurrence of deformations and crackings within the building which seriously jeopardised the safety of its further usefulness, the following renovation works were recommended:

a) execution of interim safety actions involved repairing impaired keystones of the window vaults and wedging the overhanging roof component for the sake of immediate relieving the people factor emergency.

b) assembly of a firm and combined supportive structure (Fig. 5), propped up by drilled piles, specifically manufactured due to the extraordinary conditions of work and ground composition under the Extension, taking into account not only widening of the piles footings and increase of the piles load capacity through injections at the level of their footings but also forming the piles casings with the use of Wolfsholtz's system.

c) performing bracings in the cracked walls of the Extension through wedging them with the roof and ceilings with the use of nine additional anchors apart from the eight ones formed earlier and application of injections to all the emerged tear lines and cracks.

At the same time, the entire building required renovation works covering: (i) smoothing the plastering the inner walls, (ii) supplementing the outlined welds in the facade of the building and cleansing it from the already existing streakings and marks, (iii) performing a new roof cladding and insulation over the Lecture hall, (iv) constructing a drainage system around the building and a horizontal anti-humidity insulation at the floor level in the basement, (v) supplementing hollow cavities in some of the cellars of the Extension with the use of the injection system.
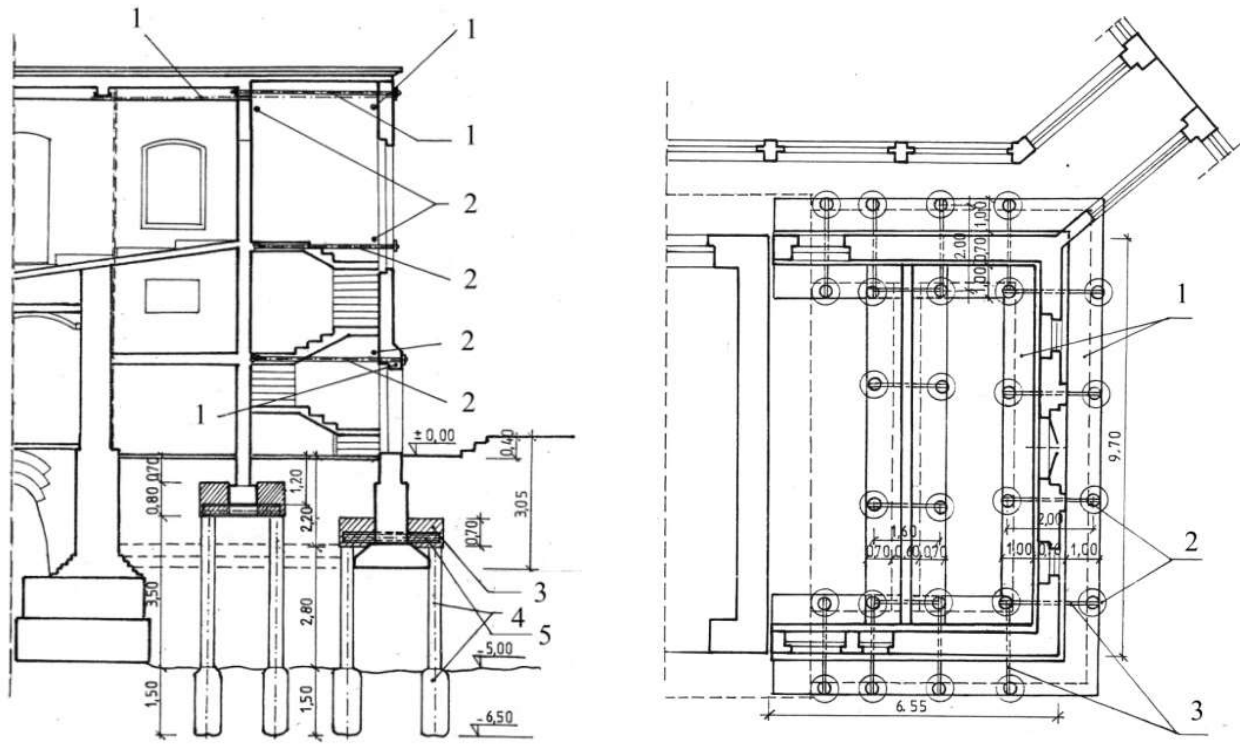

Fig. 5. Strengthening of the Extension foundations - vertical and horizontal cross-section (1 existing anchors, 2 - recommended new anchors, 3 - reinforced concrete supporters, 4 - reinforced concrete piles, 5 - steel girders connecting the foundations with the piles)

\subsection{Reinforcement works in the Extension to the north wing of the pathological anatomy building}

In the course of the analysis conducted to investigate the conditions of the Extension foundations in accordance with the existing norms [1,2 and 3] it was revealed that due to 
extreme exceeding of critical steress thresholds regarding the ground under its foundations, the risk of both further displacement of plastic soils NM from under the load-bearing walls and further subsidence should have been taken into account. In light of the continued need to utilise the Extension emboding a part of the Lecture hall together with the staircase and the lavatories, it appeared necessary to execute crucial supporting works as soon as possible. They involved the structure of the building and were mainly connected with the load-bearing walls stabilization. The envisaged reconstruction operations covered a range of technical actions discussed beneath:

a) Relocation of excessive steress of load-bearing walls foundations from inadequate ground layer NM according to its load bearing capacity onto a solid substrate with adequate load bearing capacity PNS with the use of supporting construction (Fig. 5) involving: (i) production of piles with a widened footing columns (load bearing capacity about $300 \mathrm{kN}$ ) - drilled in pairs on both sides of the foundations - to a depth of about 1.0-1.5m below the load bearing roof of the soil (PNS) but over the ground water table, (ii) production of piles elements in order to be able to insert the ground strengthening injection under pressure at the level of the pile column footing. Next, it was recommended to manufacture the reinforced pile shaft of liquid concrete under pressure (Wolfsholtz's system) up to a level of a girder passing through a slot in a wall, (iii) setting steel girders passing through the produced slots in the walls and cropped up via wedges on previously prepared pairs of piles, (iv) production of a composite (steel - reinforced concrete) construction taking the loads over from the walls and transmitting them onto the pile pairs.

b) Due to multiple crackings of walls, roof and ceilings, it was also necessary to perform an additional wall bracing of the Extension structure.

c) For this purpose, placed nine additional anchors envisaged, in the way shown in Fig.5.

d) The remaining damage of the building, in the form of tear lines and craks, was repaired with the injection system after the completion of the above discussed structure strenghtening.

\subsection{Renovation works of the Connector}

As a single - storey building and despite multiple ckracks, the Extension (Part no. 4) did not pose a serious safety risk for the people. The majority of cracks were induced by subsidence of the Extension walls which also served as a supporting measure for the Connector's roof. Certain wall movements concerning the outer wall of the Connector were unavoidable. Therefore the passive solution was chosen which concerned:

a) after the support construction for the Extension building and providing rainwater drainage arrangement as well as applying the damp-proof course, it was possible to suspect that the cracks would undergo cessation after some time,

b) during the completion phase of renovation works connected with the anatomy building, it was mandatory to fill all the fissures with a flexible inject mass, vulnerable maintain minor openings.

\section{Conclusions}

The conducted tests together with the analysis of foundations settlement conditions, the arising damage and deformities enabled to stipulate their causes and eventually, to execute suitable repair proceedings. Major reasons of the emerging damage involve:

a) substantial differences concerning subsidence resulting from the application of radically distant methods of founding the Extension (Part no.3) and the Lecture hall (part no.1). Foundations were constructed in various historical phases, in distinct 
shapes, at different levels of depth and on disparate ground layers. Simultaneously, there were attempts to conceal all the variations with a unified texture or colouring applied to facades and rooms.

b) the deformation which occurred in the Extension (Part no.3) and the Connector (Part no.4) resulted from setting their foundations on poorly and unevenly compacted mountings of sandy soils characterised by soft-plastic and liquid consistency grounds NN and NM (Fig.3).

c) ground water volatility (ranging between $\pm 6.0 \mathrm{~m}$ ) depending on the river water level was a crucial destabilization factor. The impact of buoyancy and grounds $N M$ suffosion phenomena led to periodical intensification or impediment of subsidence processes as well as changeability of load bearing capacities,

d) emergence of the building damage was induced firstly by failing to complete the dilatation proceedings between the parts Extension (Part no.3) - Connector (Part no.4) and a stable main building (Part no.1) and secondly by all the earlier discussed destabilization factors.

Basing on the research findings, a concept was developed which evolved around supporting the walls of the building to ensure failure-free operation of the constructions for the succeeding years. The scheme invloved: (i) providing support for the foundations of the Extension on a stable ground with the application of piles and steel-reinforced concrete pile combining with the foundations, (ii) anchoring the walls of the Extension within the roof of the stable part of the building, (iii) performing repair works of the roof and its insulation, (iv) injecting wall slots and cracks of the building as well as filling the defects.

The real damage reasons concerning the discussed building was neglected during a few earlier attempts to unsuccessfully reconstruct the buiding. As regards the outer appearance of the building, it seemed unified. However, only after the extensive investigation into the history of the building completion, it was possible to distribute entirely different components. Adoption of non-eligible analogies regarding the method of founding the previously studied building parts resulted in creating fallacies. Yet, an in-depth, historically-constructional analysis associated with the results of geotechnicallyhydrological tests paved the way to comprehend the phenomena responsible for the construction damage. Therefore, it is always crucial to run a complex and thorough analysis of the emerging damage causes, especially when it concerns a historical building and the extension proceedings were performed in stages, in various historical epochs. The recommendations developed and executed on the premises of the following research findings successfully influenced the cessation of further damage occurring in the building. The adequancy of the established diagnosis concerning the reasons of damage and of the adapted repair solutions were proved by succeeding longitudinal observations of the object under question.

\section{References}

1. PN-81-B-03020, Building soils. Foundation bases. Static calculation and design, $(1981)$

2. PN-83/B-02482, Foundations. Bearing capacity of piles and pile foundations, (1983)

3. Z.Wiłun, Outline of the geotechnics (W.K. i Ł, Warsaw, 1982)

4. P.Johansson, P.Wahlgren, Renovation of buildings from before 1945 :status assessment and energy efficiency measures, Energy Procedia 132, 951-956 (2017)

5. P.J.Godwin, Building Conservation and Sustainability in the United Kingdom, Procedia Engineering 20, 12-21 (2011) 
6. J.Przewlocki, M.Zielinska, Analysis of the Behavior of Foundations of Historical Buildings, Procedia Engineering 161, 362-367 (2016)

7. M.Hocova, M.Cangár, S.Badurovac, Technological aspects of reconstruction of historical buildings, Procedia Engineering 111, 302-310 (2015) 